\title{
(C) OPEN ACCESS \\ Treatment of end-stage renal disease with continuous ambulatory peritoneal dialysis in rural Guatemala
}

\author{
Jillian Moore, 1,2 Pablo Garcia, ${ }^{2,3}$ Peter Rohloff, 2,4 David Flood ${ }^{2,5}$
}

${ }^{1}$ Harvard Medical School, Boston, Massachusetts, USA 'Wuqu' Kawoq, Santiago Sacatepéquez, Guatemala ${ }^{3}$ Department of Medicine, Saint Peter's University Hospital, New Brunswick, New Jersey, USA ${ }^{4}$ Department of Medicine, Brigham and Women's Hospital, Boston, Massachusetts, USA ${ }^{5}$ Departments of Medicine and Pediatrics, University of Minnesota, Minneapolis, Minnesota, USA

Correspondence to Dr Peter Rohloff, prohloff@partners.org

Accepted 9 April 2018

Check for updates

To cite: Moore J, Garcia P Rohloff P, et al. BMJ Case Rep Published Online First: [please include Day Month Year]. doi:10.1136/bcr-2017 223641

\begin{abstract}
SUMMARY
A 42-year-old indigenous Maya man presented to a non-profit clinic in rural Guatemala with signs, symptoms and laboratory values consistent with uncontrolled diabetes. Despite appropriate treatment, approximately 18 months after presentation, he was found to have irreversible end-stage renal disease (ESRD) of uncertain aetiology. He was referred to the national public nephrology clinic and subsequently initiated home-based continuous ambulatory peritoneal dialysis. With primary care provided by the non-profit clinic, his clinical status improved on dialysis, but socioeconomic and psychological challenges persisted for the patient and his family. This case shows how care for people with ESRD in low- and middle-income countries requires scaling up renal replacement therapy and ensuring access to primary care, mental healthcare and social work services.
\end{abstract}

\section{CASE PRESENTATION}

A 42-year-old indigenous Maya man with a 6-year history of type 2 diabetes presented to a non-profit clinic in a rural agricultural town in Guatemala with weight loss, fatigue and weakness. Six years prior to presentation, he had been diagnosed with diabetes and later admitted to a regional hospital in a coma due to a hyperglycaemic crisis. After discharge from the hospital, the patient lost his job as a construction worker. As he could not afford antidiabetic medications or private physician fees, he abandoned outpatient treatment until being referred to the non-profit clinic.

On presentation, his examination was notable for cachexia, inability to ambulate and severe peripheral neuropathy. His weight was $32.7 \mathrm{~kg}$ with a body mass index of $14.5 \mathrm{~kg} / \mathrm{m}^{2}$, and his blood pressure was 90/60 mm Hg. Random fingerstick blood glucose was over $600 \mathrm{mg} / \mathrm{mL}$ (normal $<200 \mathrm{mg}$ ) $\mathrm{mL}$ ), serum creatinine was $1.1 \mathrm{mg} / \mathrm{dL}$ (normal range $0.7-1.2 \mathrm{mg} / \mathrm{dL}$ ) and urine albumin to creatinine ratio (ACR) was $40 \mathrm{mg} / \mathrm{g}$ (normal $<30 \mathrm{mg} / \mathrm{g}$ ). Haemoglobin A1c testing was not available. He had undergone bilateral cataract surgery approximately 2 years prior to presentation, and ophthalmologic evaluation at that time did not reveal retinopathy. The patient was started on insulin NPH. Following his initial presentation, the non-profit clinic procured point-of-care haemoglobin A1c testing, which resulted at $7.0 \%$ (normal range 3.9\%-6.5\%) 12 months after presentation. Repeat screening creatinine at this time was again normal.
Approximately 18 months after his initial presentation, the patient reported persistent difficulty gaining weight, as well as interval development of severe nausea and anorexia. An evaluation for failure to thrive was initiated at a higher-level laboratory in the regional capital. Results were notable for a serum creatinine of $7.57 \mathrm{mg} / \mathrm{dL}$ (glomerular filtration rate $8.5 \mathrm{~mL} / \mathrm{min} / 1.732$ ) and blood urea nitrogen of $68.0 \mathrm{mg} / \mathrm{dL}$ (normal range $6.0-21 \mathrm{mg} /$ $\mathrm{dL}$ ), which were confirmed on repeat. Serum potassium, liver function tests, $\mathrm{C}$ reactive protein, thyrotropin, HIV, viral hepatitis antibodies, antinuclear antibodies, serum protein electrophoresis and urinalysis (with the exception of the presence of glycosuria) were normal. Haemoglobin was $7.3 \mathrm{mg} /$ $\mathrm{dL}$ (normal range $12-16 \mathrm{mg} / \mathrm{dL}$ ) with normal mean corpuscular volume. A renal ultrasound showed bilateral atrophic kidneys with increased echogenicity, two small non-obstructive echogenic foci suggestive of kidney stones and no significant hydronephrosis. Additional information obtained at this time confirmed that the patient had no known history of hypertension, urinary tract infections (UTIs), nephrolithiasis or exposure to nephrotoxic agents.

The patient was referred to the National Centre for Chronic Renal Disease (UNAERC), an institution in Guatemala City serving as the public nephrology centre. At UNAERC, the aetiology of his end-stage renal disease (ESRD) was not definitively elucidated, and a kidney biopsy was not pursued given the chronic and irreversible nature of his renal disease. Renal replacement therapy was recommended, and the patient was presented two options: twice-weekly haemodialysis at UNAERC, or continuous ambulatory peritoneal dialysis (CAPD) multiple times daily in his home. He chose CAPD, as limited mobility and finances precluded him from travelling to Guatemala City, a 3-hour bus trip each way. The patient initiated home CAPD after an abdominal catheter was placed and a sterile dialysis room was constructed in his home.

As of the writing of this case report, the patient has performed CAPD four times per day for 3 years. Clinically, he has improved considerably. He has more energy, can ambulate and has gained $10 \mathrm{~kg}$. $\mathrm{He}$ has experienced no episodes of peritonitis. However, due to severe peripheral neuropathy and weakness, he must always be accompanied outside the home, sleeps with difficulty and requires assistance with most self-care activities in addition to his dialysis exchanges. He has not returned to work. 
Socioeconomically and psychologically, the patient and his family have struggled. His wife cannot hold a regular job given her role as primary caregiver, and Guatemala does not have a national disability programme to support individuals who cannot work due to illness or injury. While UNAERC provides free clinical consultations and dialysis supplies, it does not cover other aspects of care including transportation, medications, nutritional supplements, primary care or emergency care. The patient and his family have subsided on donations from the non-profit clinic and their local church, as well as the meagre wages his wife earns weaving belts (US\$33 monthly). The patient has four young children, and he worries constantly about the future. His chronic diseases have caused him to feel distress, helplessness and shame, yet he has not been formally evaluated for a mood or anxiety disorder given the lack of mental health practitioners in his rural town.

\section{GLOBAL HEALTH PROBLEM LIST}

1. Many people in rural areas of low- and middle-income countries (LMICs) do not receive adequate primary healthcare due to poverty, geographic barriers and health system limitations. Underfunded rural public health systems struggle to prevent, detect and manage chronic diseases, including chronic kidney disease (CKD).

2. Given obstacles to renal transplantation, dialysis is often the only feasible option for patients with ESRD in LMICs. Access to dialysis is limited in rural areas, and there is great need for community-based dialysis programmes.

3. Debilitating illnesses like ESRD cause economic, social and psychological burdens for patients and their families in LMICs. Access to primary care, mental healthcare and social work services is important for these patients and their families.

\section{GLOBAL HEALTH PROBLEM ANALYSIS}

This case describes a patient who developed ESRD of uncertain aetiology and who now requires dialysis. This story is increasingly common in LMICs like Guatemala, as a rising prevalence of nephropathies of various causes confers an increasing burden of ESRD and an urgent need to expand access to renal replacement therapy. However, many public health systems do not have the resources or capacity to provide comprehensive care to patients with ESRD. Given the rising rates of renal disease in LMICs, it is essential to reflect on why patients develop CKD, what can be done to prevent this condition, and how to best care for patients when disease progresses to its end stage.

\section{CKD in Guatemala}

Guatemala is an LMIC in Central America with a population of 16 million people. While the epidemiology and risk factors for renal disease are not well understood in Guatemala, available evidence including from the Global Burden of Disease Study suggests that, as in other LMICs, the burden of CKD is significant and rising. ${ }^{12} \mathrm{WHO}$ estimates that renal failure mortality in Guatemala in 2007 was 24.7 per 100000 people, one of the highest rates in the Americas. ${ }^{3}$ In the Latin American region, diabetes has been identified as the leading cause of CKD requiring dialysis, and, as of 2013 in Guatemala, 30\% of new patients requiring renal replacement therapy had diabetes. ${ }^{4}$ Our organisation previously reported high rates of CKD in a rural diabetes cohort, ${ }^{56}$ data which were consistent with evidence from Mexico showing a strong link between diabetes and renal cause of death.
For the patient in this case, the aetiology of CKD remains unknown, and a wide differential includes diabetic nephropathy, nephrotoxic exposure, chronic nephrolithiasis, chronic UTIs and other causes. The patient has a 6-year history of uncontrolled diabetes and has experienced diabetes complications such as hyperglycaemic crisis and severe peripheral neuropathy. However, he does not meet criteria for diabetic kidney disease given that he had no history of diabetic retinopathy, did not have severely increased albuminuria (previously known as macroalbuminuria, ACR $>300 \mathrm{mg} / \mathrm{g}$ ) and had a more rapid progression of renal disease than would typically be expected from diabetes alone. ${ }^{8} \mathrm{He}$ also did not have a history or laboratory evidence suggestive of other common causes of ESRD-including hypertension, UTIs or nephrotoxic ingestion. Although echogenic foci were found on renal ultrasound, the pattern was not consistent with nephrocalcinosis, and the presence of non-obstructing kidney stones without hydronephrosis in a patient denying a history of symptoms of renal colic makes chronic nephrolithiasis seem less likely as the primary aetiology for his CKD.

In recent decades, there has been an increasing incidence of renal disease of uncertain aetiology in Central America observed in male agricultural workers in coastal areas. This entity has been termed 'CKD of non-traditional aetiology' (CKDnT) and is a source of active research throughout the region. The Pan American Health Association (PAHO) recently released a report on CKDnT epidemiology, consensus case definitions and methods for surveillance. ${ }^{9}$ In Guatemala, dialysis enrolment rates may be higher along the southwestern coast. ${ }^{1011}$ However, epidemiological studies using dialysis registries are susceptible to confounding as indigenous Maya people, like this patient, tend to live in highland rather than coastal towns and also face barriers to accessing dialysis. ${ }^{12}$ The patient described in this case does not meet PAHO technical criteria for a 'confirmed clinical case of CKDnT' given the presence of diabetes with diabetic neuropathy. ${ }^{9}$

\section{Renal replacement therapy in rural Guatemala}

Once a person develops ESRD, the only means of survival are through renal replacement therapy, which includes dialysishaemodialysis or peritoneal dialysis - or renal transplantation. Like other nephrology-related medicines and technologies, renal replacement therapy is unequally distributed around the world. Millions of people die prematurely each year because they cannot access dialysis or transplantation, particularly in LMICs. ${ }^{1314}$ Even among those who can access renal replacement therapy, there are significant outcome disparities by socioeconomic status and geography. ${ }^{13} 1516$

Kidney transplantation confers survival and quality of life advantages over dialysis. ${ }^{17}$ The first renal transplantation programme in Guatemala was launched in the 1980s in the Social Security health system. ${ }^{18}$ In 2015 , according to data from the National Nephrology Association, there were 117 total kidney transplantations: 68\% were performed in the public sector, $15 \%$ of transplant recipients were children and $17 \%$ involved deceased-donor kidneys. ${ }^{19}$ The overall renal transplantation rate in Guatemala in 2013 was $5.6 \%$, which is lower than the overall rate in Latin America of $19.8 \% .^{4}$ Barriers to expanding access to renal transplantation include limitations in public sector funding, lack of structured waiting lists, incomplete coverage of post-transplant immunosuppression therapy, opt-in organ donation laws and minimal health protection for living donors. ${ }^{20}$

In Latin America, rates of dialysis are rising sharply, and haemodialysis is the modality of choice in $90 \%$ of cases. ${ }^{4}$ Guatemala is unique in that more than half of dialysis patients 
undertake peritoneal dialysis, giving the country one of the highest per capita rates of peritoneal dialysis in the world. ${ }^{21}$ The public nephrology centre, UNAERC, manages a dialysis caseload of approximately 4500 people, of which two-thirds use CAPD. ${ }^{22}$ Advantages of CAPD over haemodialysis include allowing rural patients to undertake therapy in their homes, requiring less infrastructure or specialised staff and not depending on the availability of rationed machines. ${ }^{23}$ Rural CAPD programmes have been reported in multiple LMICs. ${ }^{24-26}$

Patients at UNAERC receive, free of charge, all supplies directly necessary for CAPD: expert nephrology consultation, catheter insertion and maintenance, dialysis solution and laboratory monitoring of dialysis function. Basic survival is the chief concern. Unfortunately, UNAERC is unable to fund treatment for many sequelae of ESRD such as anaemia, mineral bone disease, hypertension, metabolic acidosis or dyslipidaemia. Additionally, the rural public healthcare system is not adequately equipped to meet the considerable primary healthcare concerns of patients with ESRD, which may include insomnia, pruritus, diabetes, hypertension, neuropathy, diarrhoea, sexual dysfunction and depression.

\section{Systemic barriers to primary care in rural Guatemala}

The Guatemalan healthcare system is marked by extreme fragmentation, privatisation and inequity. ${ }^{12}$ The rural public healthcare system was established following the 1996 Peace Accords, which formally ended a 36-year civil war. The system was designed primarily to deliver basic preventative services to mothers and children. ${ }^{27}$ While the disease landscape has shifted considerably since 1996, with chronic conditions comprising an increasingly significant burden, the health system has not been reoriented to this new epidemiology. Overall, the public health system in Guatemala is persistently underfunded; as a per cent of GDP, the country has the lowest government spending on health in Central America. ${ }^{28}$

Like the patient in this case report, over half of Guatemalans are indigenous Maya, a group that faces formidable socioeconomic, linguistic and geographic barriers to healthcare. ${ }^{12}$ Indigenous populations have high rates of poverty, limited access to education and poor health as measured by a range of indicators including infant mortality, child malnutrition and access to prenatal care. ${ }^{29}$ The most reliable data on health disparities between indigenous and non-indigenous people derive from reproductive health surveys, which generally suggest that such poorer health indicators in indigenous groups are not solely explained by poverty and rural residence. ${ }^{29}$ There are limited studies on the prevalence and outcomes of diseases like diabetes, cancer or CKD in indigenous areas. Available data show that ethnic disparities exist in both paediatric and adult populations. ${ }^{30-32}$

In theory, all Guatemalans can access primary healthcare either within the network of free clinics and hospitals operated by the Ministry of Health (MOH), through a system of employment-based insurance at designated facilities, or at military hospitals. However, in reality, only a small proportion of the population has public or private insurance, particularly in rural areas, and $\mathrm{MOH}$ healthcare is limited by resource constraints. For example, patients at $\mathrm{MOH}$ health centres may be sent to purchase basic medications or laboratory tests, and certain resources like insulin are typically only available at regional referral hospitals. With these shortcomings in the public health system, many Guatemalans seek care in the private sector. While private sector care is considered more responsive than care delivered at public health centres, private care is expensive and fragmented. In general, the poorest and most marginalised patients are unable to access regular primary care for chronic diseases like diabetes or CKD.

This case illustrates many of the major challenges in accessing chronic disease care for both diabetes and CKD in rural Guatemala. Prior to seeking care at the non-profit clinic, the patient had entered a sickness-poverty cycle due to uncontrolled diabetes: he became too sick to work, then too poor pay for quality healthcare and medications and consequently he became even sicker. On developing CKD, there was no coordination between the public nephrology clinic and his local health centre and no primary care infrastructure to manage his associated symptoms and conditions. His indigenous ethnicity may have also contributed to his poor diabetes control and difficulty accessing highquality primary care services.

While strengthening the rural public health system would be the most powerful approach to improve primary care in rural Guatemala - and to thereby both prevent and manage chronic disease-in the current political and economic environment, it is difficult to imagine the government dramatically increasing public outlays for chronic disease care. Care coordination and intensive social work interventions are potential strategies to assist patients with ESRD and other complex care needs, and there are examples of such programmes in Guatemala. ${ }^{30} 313334$ However, scaling up such interventions would require massive philanthropic or public sector investments.

The patient in this case is fortunate to live in a country providing public dialysis services to impoverished patients with ESRD from rural areas. Nevertheless, although dialysis has prolonged his life, this therapy has not necessarily nurtured his quality of life. With a national kidney transplantation rate of less than $6 \%{ }^{4}$ most Guatemalans with ESRD, like the patient in this case, have no reasonable hope for life beyond dialysis. We therefore should consider what makes life worth living for those able to successfully access dialysis in places like rural Guatemala.

\section{Lived experiences of ESRD}

The typical trajectory of ESRD resembles those of other organ failures: chronic, progressive debility interposed by episodes of acute decompensation, with death often sudden and unexpected. Like the patient in this report, people on dialysis can survive for years during which they may endure fatigue, weakness, pruritus, insomnia, pain, depression and functional impairment-in addition to the symptom burdens of comorbid conditions. These patients must adhere to a demanding dialysis regimen in order to live, yet they cannot be certain what their lives will entail or how long they will survive.

The patient in this case is a poor, indigenous man whose chronic illnesses have limited him from employment as a construction worker. He lives in Guatemala, a nation infused with legacies of colonialism, racism and oppression. Historically, indigenous people have been viewed by the state primarily as a resource from which to extract unpaid physical labour for the production of commodities and public works. ${ }^{35}$ Today, while indigenous people in Guatemala have more rights than in previous generations, the indigenous poor still often sell their labour in the informal economy. Rural men, like this patient, learn to maintain strong bodies to augment their labour potential and their ability to provide for their families. Hence, conditions of poverty and marginalisation lead to chronic illness and impairment, and also cause chronic illness and impairment to be felt more severely. ${ }^{36}$ 
Chronic diseases like ESRD often preclude patients from fulfilling expected roles and may result in altered social identities and self-concepts. ${ }^{37}$ The patient in this report tearfully described feeling like 'a little baby' unable to provide for his family or carry out basic activities of daily living without assistance from his wife and children. Indeed, those facing illness and impairment may perceive a loss of status within their families and communities, especially when moral worth is tied to a masculinity grounded in strength, endurance and the ability support others-as is common for men in rural Guatemala. Patients on dialysis may also endure tedium - an emptiness of time-as their treatment regimen 'threatens to overcome, and for some patients, to become the life it extends. ${ }^{38}$ The patient in this report has found meaning and joy being with his children, singing and praying, but others may not be similarly incorporated into family and community life.

As described in this report, patients on dialysis face significant social and occupational limitations from their time-consuming yet life-supporting treatment. Given the rising number of patients on dialysis in Guatemala and elsewhere who will never receive a kidney transplant, 'health-related quality of life'-how patients perceive illness and treatment to affect their physical, mental, spiritual, emotional, social and functional well-being-has become an important dialysis outcome measure. ${ }^{39}$ Standardised instruments have not been validated in most LMICs, where the focus is more often on basic treatment provision and survival. ${ }^{40}$ Nonetheless, for patients on dialysis, poor health-related quality of life, ${ }^{41}$ discrepancies between expected and received social support $^{42}$ and depressive symptoms ${ }^{43}$ have each been found to be associated with increased mortality.

\section{Patient's perspective}

- 'My dream would be that my kidneys would work again, and that I could stop dialysis... One of the hardest things for us are trips to nephrology appointments in Guatemala City—getting up at 2:00 a.m., bringing my wheelchair, and the long bus rides... You have to have faith in God and a lot of patience with this disease. When I heard the news that my kidneys were failing, I felt that my life was over. It's an incurable disease, and there isn't any way for my kidneys to recover. The only option is dialysis, which I will have to do for the rest of my life. Sometimes, I feel like I just don't want to do dialysis anymore. But when the time comes to do my exchanges, I confront those feelings and just keep going. Like I said, you have to have patience with this disease.'

\section{Learning points}

- Health systems in resource-limited countries may struggle to prevent, detect and manage chronic diseases like diabetes and chronic kidney disease.

- Worldwide, rising numbers of patients with end-stage renal disease (ESRD) require expansion of dialysis and renal transplantation, especially in rural areas.

- ESRD has significant impacts on the quality of life of patients and their families.

- Care for patients with ESRD requires meeting the comprehensive needs of these patients, including access to primary care, mental healthcare and social work services.
As with other chronic conditions, the impacts of ESRD are not limited to a single patient but rather permeate households and communities. Patients who once earned wages to support their families can no longer work, requiring household roles to shift to replace lost incomes. Furthermore, chronic illnesses like ESRD entail direct costs for medical treatment and indirect costs such as the uncompensated labour of family members who provide caregiving. In countries like Guatemala without universal disability or health insurance programmes, those in poverty are exquisitely sensitive to out-of-pocket catastrophic health expenditures. ${ }^{44}$ The patient in this case has successfully performed dialysis for multiple years, in part due to material support received from a local church, extended family and a non-governmental organisation. Other ESRD patients in poverty who lack such support are unlikely to successfully access and sustain dialysis in Guatemala.

In addition to providing resources and basic income, the families and communities of patients with ESRD must often provide intimate care, including feeding, bathing, grooming, dressing and toileting. Although gender roles are shifting, ${ }^{46} 46$ in rural Guatemala, as in many cultures, there is a gendered division of labour in which women perform reproductive labour in the private sphere-including tending to the young, elderly and sick-and men perform productive labour in the public sphere. ${ }^{47}$ For the man in this case, his wife provides him constant and intimate care, and also works to generate income to provide for their four children.

In summary, the rising rate of patients with ESRD in LMICs will require rapidly scaling up nephrology care and interventions like dialysis and renal transplant. As this case illustrates, comprehensive ESRD care also must include access to primary care, mental healthcare and social work services.

Contributors JM and DF conceptualised the manuscript and wrote the first draft. DF and PR led clinical care of the patient. PR and PG critically revised the manuscript.

Funding The authors have not declared a specific grant for this research from any funding agency in the public, commercial or not-for-profit sectors.

\section{Competing interests None declared.}

\section{Patient consent Obtained.}

Provenance and peer review Not commissioned; externally peer reviewed.

Open Access This is an Open Access article distributed in accordance with the Creative Commons Attribution Non Commercial (CC BY-NC 4.0) license, which permits others to distribute, remix, adapt, build upon this work non-commercially, and license their derivative works on different terms, provided the original work is properly cited and the use is non-commercial. See: http://creativecommons.org/ licenses/by-nc/4.0/

(c) BMJ Publishing Group Ltd (unless otherwise stated in the text of the article) 2018. All rights reserved. No commercial use is permitted unless otherwise expressly granted.

\section{REFERENCES}

1 Institute for Health Metrics and evaluation (IHME). GBD compare data visualization Seattle, Wa: IHME, University of Washington, 2016. http://vizhub. healthdata.org/gbdcompare. (accessed 22 Mar 2018).

2 Jager KJ, Fraser SDS. The ascending rank of chronic kidney disease in the global burden of disease study. Nephrol Dial Transplant 2017;32:ii121-ii128.

3 PAHO and WHO. Renal Failure and Chronic Kidney Disease (CKD) mortality visualization. 2014. http://www.paho.org/hq/index.php?option=com_content\&view= article\&id=9402\&ltemid=41166\&lang=en (accessed 22 Mar 2018)

4 Cusumano AM, Rosa-Diez GJ, Gonzalez-Bedat MC. Latin American dialysis and transplant registry: experience and contributions to end-stage renal disease epidemiology. World J Nephrol 2016;5:389-97.

5 Flood D, Mux S, Martinez B, et al. Implementation and outcomes of a comprehensive type 2 diabetes program in rural Guatemala. PLoS One 2016:11:e0161152.

6 Flood D, Garcia P, Douglas K, et al. Screening for chronic kidney disease in a community-based diabetes cohort in rural Guatemala: a cross-sectional study. BMJ Open 2018;8:e019778. 
7 Alegre-Díaz J, Herrington W, López-Cervantes M, et al. Diabetes and Cause-Specific Mortality in Mexico City. N Eng/ J Med 2016;375:1961-71.

$8 \mathrm{KDOQI}$ Clinical practice guidelines and clinical practice recommendations for diabetes and chronic kidney disease. Am J Kidney Dis 2007:49(2 Suppl 2):S12-154.

9 Pan American Health Organization. Epidemic of Chronic Kidney Disease in Agricultural Communities in Central America. Case definitions, methodological basis and approaches for public health surveillance. Washington, DC: PAHO, 2017. http://iris. paho.org/xmlui/handle/123456789/34132. (accessed 22 Mar 2018).

10 Laux TS, Barnoya J, Cipriano E, et al. Prevalence of chronic kidney disease of nontraditional causes in patients on hemodialysis in southwest Guatemala. Rev Panam Salud Publica 2016;39:186-93.

11 Laux TS, Barnoya J, Guerrero DR, et al. Dialysis enrollment patterns in Guatemala: evidence of the chronic kidney disease of non-traditional causes epidemic in Mesoamerica. BMC Nephrol 2015;16:54.

12 Chary A, Rohloff P, eds. Privatization and the New Medical Pluralism: Shifting Healthcare Landscapes in Maya Guatemala. Lanham, Maryland: Lexington Press, 2015.

13 Liyanage T, Ninomiya T, Jha V, et al. Worldwide access to treatment for end-stage kidney disease: a systematic review. Lancet 2015;385:1975-82.

14 Anand S, Bitton A, Gaziano T. The gap between estimated incidence of end-stage renal disease and use of therapy. PLoS One 2013;8:e72860.

15 Ashuntantang G, Osafo C, Olowu WA, et al. Outcomes in adults and children with end-stage kidney disease requiring dialysis in sub-Saharan Africa: a systematic review. Lancet Glob Health 2017:5:e408-17.

16 Robinson BM, Akizawa T, Jager KJ, et al. Factors affecting outcomes in patients reaching end-stage kidney disease worldwide: differences in access to renal replacement therapy, modality use, and haemodialysis practices. Lancet 2016:388:294-306.

17 Tonelli M, Wiebe N, Knoll G, et al. Systematic review: kidney transplantation compared with dialysis in clinically relevant outcomes. Am J Transplant 2011;11:2093-109.

18 Lou-Meda R. La Nefrología en Guatemala: Una Historia Vivida: Master's Thesis, Universidad de San Carlos de Guatemala, 2011. http://www.repositorio.usac.edu.gt/ 1206/1/07_2116.pdf (accessed 22 Mar 2018).

19 Piedrasanta Batz Jl, Galindo Castillo F, Gomez Quiroa DA, et al. Trasplante renal como opción terapéutica en Guatemala. Asociación de Medicina Interna de Guatemala 2017;21:33-8.

20 Garcia-Gallont R, Matesanz R, Delmonico FL. Organ donation and transplantation in Central America. Transplantation 2015;99:459-60.

21 Jain AK, Blake P, Cordy P, et al. Global trends in rates of peritoneal dialysis. J Am Soc Nephrol 2012;23:533-44.

22 Unidad Nacional de Atención al Enfermo Renal Crónico (UNAERC). Pacientes activos por programa y consulta del mes según bioestadísticas. 2015 http://unaerc.gob.gt/ estadisticas/pacientes-activos-por-programa-y-consulta-del-mes-segun-bioestadisticas (accessed 24 Oct 2017).

23 Abraham $\mathrm{G}$, Varughese $\mathrm{S}$, Mathew $\mathrm{M}$, et al. A review of acute and chronic peritoneal dialysis in developing countries. Clin Kidney I 2015;8:310-7.

24 Nanayakkara N, Wazil AWM, Gunerathne L, et al. Tackling the fallout from chronic kidney disease of unknown etiology: why we need to focus on providing peritoneal dialysis in rural, low-resource settings. Kidney Int Rep 2017;2:1-4.

25 Jiang Z, Yu X. Advancing the use and quality of peritoneal dialysis by developing a peritoneal dialysis satellite center program. Perit Dial Int 2011;31:121-6.

26 Sanabria M, Devia M, Hernández G, et al. Outcomes of a peritoneal dialysis program in remote communities within Colombia. Perit Dial Int 2015;35:52-61.
27 Maupin JN. 'Fruit of the accords': healthcare reform and civil participation in Highland Guatemala. Soc Sci Med 2009:68:1456-63.

28 Avila C, Bright R, Gutierrez J, et al. Guatemala Health System Assessment. Bethesda, MD: Health Finance \& Governance Project, Abt Associates Inc, 2015. https://www. usaid.gov/sites/default/files/documents/1862/Guatemala-HSA\%20_ENG-FULLREPORT-FINAL-APRIL-2016.pdf (accessed 22 Mar 2018).

29 Ministerio de Salud Pública y Asistencia Social, Instituto Nacional de Estadística, and ICF International. VI Encuesta Nacional de Salud Materno Infantil (ENSMI) 20142015: informe final. Guatemala: MSPAS, INE, ICF, 2017.

30 Alvarez E, Seppa M, Rivas S, et al. Improvement in treatment abandonment in pediatric patients with cancer in Guatemala. Pediatr Blood Cancer 2017; 64:e26560

31 Ramay BM, Cerón A, Méndez-Alburez LP, et al. Factors associated to acceptable treatment adherence among children with chronic kidney disease in Guatemala. PLoS One 2017:12:e0186644.

32 Chary A, Greiner M, Bowers C, et al. Determining adult type 2 diabetes-related health care needs in an indigenous population from rural Guatemala: a mixed-methods preliminary study. BMC Health Serv Res 2012;12:476.

33 Flood DC, Chary AN, Austad K, et al. A patient navigation system to minimize barriers for peritoneal dialysis in rural, low-resource settings: case study from Guatemala. Kidney Int Rep 2017;2:762-5.

34 Chary A, Flood D, Austad K, et al. Accompanying indigenous Maya patients with complex medical needs: A patient navigation system in rural Guatemala. Healthc 2017.

35 McCreery D. Rural Guatemala, 1760-1940. Stanford, California: Stanford University Press, 1994.

36 Connell R. Southern Bodies and Disability: re-thinking concepts. Third World Quarterly 2011:32:1369-81.

37 Tijerina MS. Mexican American women's adherence to hemodialysis treatment: a social constructivist perspective. Soc Work 2009:54:232-42.

38 Russ AJ, Shim JK, Kaufman SR. "Is there life on dialysis?": time and aging in a clinically sustained existence. Med Anthropol 2005;24:297-324.

39 Mitema D, Jaar BG. How can we improve the quality of life of dialysis patients? Semin Dial 2016;29:93-102.

40 Awuah KT, Finkelstein SH, Finkelstein FO. Quality of life of chronic kidney disease patients in developing countries. Kidney Int Supp/ 2013;3:227-9.

41 Mapes DL, Bragg-Gresham JL, Bommer J, et al. Health-related quality of life in the Dialysis Outcomes and Practice Patterns Study (DOPPS). Am I Kidney Dis 2004;44(5 Suppl 2):54-60.

42 Thong MS, Kaptein AA, Krediet RT, et al. Social support predicts survival in dialysis patients. Nephrol Dial Transplant 2007;22:845-50.

43 Farrokhi F, Abedi N, Beyene J, et al. Association between depression and mortality in patients receiving long-term dialysis: a systematic review and meta-analysis. $\mathrm{Am} J$ Kidney Dis 2014:63:623-35.

44 Bowser DM, Mahal A. Guatemala: the economic burden of illness and health system implications. Health Policy 2011;100:159-66.

45 Metz BE, Webb MF. Historical sediments of competing gender models in indigenous Guatemala. In: Gelfer J, ed. Masculinities in a Global Era. New York, NY: Springer, 2014:193-211.

46 Moore J, Webb MF, Chary A, et al. Aid and gendered subjectivity in rural Guatemala. Dev Stud 2017;53:2164-78.

47 Ehlers TB. Silent looms: Women and Production in a Guatemalan town. Austin: University of Texas Press, 2000.

Copyright 2018 BMJ Publishing Group. All rights reserved. For permission to reuse any of this content visit

http://group.bmj.com/group/rights-licensing/permissions.

BMJ Case Report Fellows may re-use this article for personal use and teaching without any further permission.

Become a Fellow of BMJ Case Reports today and you can:

- Submit as many cases as you like

- Enjoy fast sympathetic peer review and rapid publication of accepted articles

- Access all the published articles

- Re-use any of the published material for personal use and teaching without further permission

For information on Institutional Fellowships contact consortiasales@bmjgroup.com

Visit casereports.bmj.com for more articles like this and to become a Fellow 